\title{
Editorial
}

\section{Role of sexually transmitted diseases in transmitting human immunodeficiency virus}

Infection with human immunodeficiency virus (HIV) in adults in Africa is predominantly due to heterosexual transmission. The first studies of the acquired immune deficiency syndrome (AIDS) in central Africa identified prostitutes and heterosexually promiscuous men as high risk groups. $^{12}$ In subsequent seroprevalence surveys in Kinshasa (Zaire), Bukoba (Tanzania), Nairobi (Kenya), and Butare (Rwanda) $27 \%$ to $88 \%$ of prostitutes were found to have antibodies to HIV (Mann et al., International Conference on AIDS, Paris, 1986)..$^{3-5}$

The role of prostitutes in the sexual transmission of HIV is apparent from studies of infected men in Kenya and Rwanda. ${ }^{4-6}$ Men with AIDS or AIDS related complex were more likely to have a history of sexual intercourse with prostitutes than were controls. ${ }^{6}$ In concurrently conducted studies of prostitutes and either male customers of prostitutes or men with sexually transmitted diseases (STDs), the prevalence of antibody to HIV has characteristically been at least two to three times higher in the prostitute groups, suggesting that these women serve as an important reservoir of HIV for sexually promiscuous men. ${ }^{457}$

The reasons for the distinctive epidemiology of HIV in Africa, with transmission being the predominantly heterosexual, are still incompletely understood. There is mounting evidence, however, that sexually transmitted diseases, epidemic in many parts of Africa, may be important cofactors for enhancing HIV transmission. HIV seropositivity in African heterosexual populations has been associated with a history of genital ulcers and a positive serological test result for Treponema pallidum (Greénblatt $e t$ al and Cameron et al, International Conference on AIDS, Washington, 1987). ${ }^{4}$ Although STDs may simply be a marker for sexual promiscuity, several recent studies suggest that genital ulcers are an independent risk factor for infection with HIV. In a prospective study of initially seronegative prostitutes in Nairobi, Kenya, seroconversion was strongly associated with one or more episodes of genital ulcer disease, after controlling for such covariables as number of sexual partners, duration of prostitution, and use of condoms (FA Plummer, personal communication).

In a second prospective study of men with STDs and recent prostitute exposure, men with genital ulcers were more likely to seroconvert during a two to six month period than were men with urethritis (Cameron et al, International Conference on AIDS, Washington, 1987 and DW Cameron, personal communication). There was a much higher rate of heterosexual transmission after a presumed single sexual exposure to a prostitute who probably had genital ulcers ${ }^{8}$ than had been estimated from studies of HIV concordance rates in stable couples in the United States, which suggested that STDs that result in genital ulceration, with disruption of the integrity of the mucosal epithelium, greatly increase the infectivity of seropositive people (Peterman et al, International Conference on AIDS, Paris, 1986)..$^{90}$ Corroborating evidence in support of this hypothesis comes from recent studies of homosexual men, which found that HIV seropositivity was associated with a history of genital, anorectal, or oral herpes, a history of syphilis, or positive serological tests for herpes simplex virus type 2 (HSV 2) or $T$ pallidum, after controlling for numbers of sexual partners (Handsfield et al, International Conference on AIDS, Washington, 1987); that HIV seroconversion was appreciably associated with anogenital lesions, in particular condylomata acuminata and anal fissures (Donovan, et al), or with HSV 2 seropositivity or seroconversion (Holmberg et al, both International Conference on STD Research, Atlanta, 1987).

The study by Van de Perre et al (p 30) provides additional information regarding the potential role of STDs in the transmission of HIV. HIV antigens were detected in OKT4+ (reacting with monoclonal antibodies against CD4) lymphocytes from vaginal and cervical secretions of nine out of 14 seropositive women, but not in genital epithelial cells. This suggests that conditions that increase the number of lymphocytes in the female genital tract, such as STDs that elicit an inflammatory response, may potentiate the risk of HIV transmission by increasing the pool of infected cells in a seropositive person or the pool of target cells in a seronegative person. Studies of genital tract shedding of HIV associated with specific STDs will provide additional information regarding the relative importance of such pathogens as Haemophilus ducreyi, HSV, T pallidum, Neisseria gonorrhoeae, and Chlamydia trachomatis in HIV transmission. The role of conditions considered to be of minor public health 
importance but that are highly prevalent, such as trichomoniasis and bacterial vaginosis, also deserve more study.

The identification of modifiable cofactors for HIV transmission has important implications for HIV control programmes. Effective and inexpensive antimicrobial treatment is available for most traditional STDs. STD treatment and control programmes, especially those aimed at prostitutes and heterosexually promiscuous men, should serve as an important adjunct to health education campaigns and the promotion of condom use in retarding the rapid spread of the HIV epidemic.

Department of Epidemiology,

JOAN KREISS

University of Washington,

Seattle, Washington, USA

Institute of Sociology,

Michel CaraëL

Free University of Brussels,

Brussels, Belgium

Manager,

Programme for Sexually Transmitted Diseases,

World Health Organisation, 1211 Geneva, 27 Switzerland

\section{References}

1 Van de Perre P, Rouvroy D, Lepage P, et al. Acquired immunodeficiency syndrome in Rwanda. Lancet 1984;ii:62-5.

2 Piot P, Quinn TC, Taelman H, et al. Acquired immunodeficiency syndrome in a heterosexual population in Zaire. Lancet 1984;ii:65-9.

3 Mhalu FS, Bredberg-Raden U, Mbena E, et al. Prevalence of HIV infection in healthy subjects and groups of patients in Tanzania. AIDS 1987;1:217-21.

4 Kreiss JK, Koech D, Plummer FA, et al. AIDS virus infection in Nairobi prostitutes: spread of the epidemic to East Africa. $N$ Engl J Med 1986;314:414-8.

5 Van de Perre P, Clumeck N, Carael M, et al. Female prostitutes: a risk group for infection with human T-cell lymphotropic virus type III. Lancet 1985;ii:524-7.

6 Clumeck N, Van de Perre P, Carael M, Rouvroy D, Nzaramba D. Heterosexual promiscuity among African patients with AIDS. N Engl J Med 1985;313:182.

7 Piot P, Plummer FA, Rey MA, et al. Retrospective seroepidemiology of AIDS virus infection in Nairobi populations. J Infect Dis 1987;155:1108-12.

8 Plummer FA, D'Costa LJ, Nsanze H, et al. Epidemiology of chancroid and Haemophilus ducreyi in Nairobi, Kenya. Lancet 1983;ii:1293-5.

9 Kreiss JK, Kitchen LW, Prince HE, Kasper CK, Essex M. Antibody to human T lymphotropic virus type III in wives of hemophiliacs: evidence for heterosexual transmission. Ann Intern Med 1985;102:623-6.

10 Padian N, Wiley J, Winkelstein W. Male-to-female transmission of human immunodeficiency virus (HIV). JAMA 1987; 258:788-90. 